\title{
Communication patterns in coordinated care planning conferences with older patients
}

\author{
Tyra Graaf, Annica Kihlgren, Margareta Ehnfors, Karin Blomberg \\ School of Health and Medical Sciences, Örebro University, Sweden \\ Correspondence: Annica Kihlgren. Address: School of Health and Medical Sciences, Örebro University, Sweden. \\ Telephone: 461-930-1496. Email: annica.kihlgren@oru.se.
}

Received: August 26, 2012

DOI : 10.5430/jnep.v3n10p35

\begin{abstract}
Background: When an older patient is discharged from a hospital in Sweden, a care plan in cooperation with the patient should be made through coordinated care planning (COCP). Previous research has described difficulties in the discharge process; consequently, it is important to develop additional knowledge and investigate both whether and how patients are given the opportunity to participate in COCP. The aim of the present study was to determine if older patients are given the opportunity to participate in COCP meetings, and if so, what characterizes these meetings.
\end{abstract}

Method: This qualitative, descriptive study is based on non-participant observation of interactions between older patients and care staff at six COCP meetings. The data collected were analyzed using directed content analysis and critical discourse analysis (CDA).

Results: The main findings indicate a lack of patient participation in all the COCP meetings held at the hospital. The dialogues in that context were less information intensive, and a professional perspective dominated. The situation in advanced home care (AHC) was the opposite; already from the outset, it was evident that the patient was the chief informant and that the patient's perspective predominated during the dialogues.

Conclusions: General differences in the way the dialogues were initiated and in how they progressed were observed between the hospital and AHC. Due to both shortage of time in health care today and financial issues, it is important to find solutions that incorporate the older patient's experiences as well as professional knowledge.

\section{Key words}

Coordinated care planning, Discharge, Patient participation

\section{I ntroduction}

The growing aging population, with its multi-diseases and multifaceted needs, in combination with a shortened time spent at the hospital, requires a safe and secure transition to other care settings in the community or the own home. In the international literature over several decades, descriptions of the discharge process include a wide variety of difficulties for older patients, such as unmet personal and practical needs as well as lack of information ${ }^{[1-7]}$.

In Sweden, for a transfer to another level of care or to the patient's home, a care plan needs to be made through coordinated care planning (COCP) according to Swedish regulations ${ }^{[8]}$. This planning should be conducted in cooperation with the Published by Sciedu Press 
older patient and is intended to coordinate further care. Swedish legislation stresses the right of patients to have major influence over their own care by expressing needs and determining how the care should be carried out. Since 1986, Swedish law has made it compulsory for a registered nurse (RN) to document the nursing foundation for a patient's COCP in that patient's health record.

The focus of the present study is on older patients' participation and communication in the interaction between staff and older patients during a COCP meeting. Participation should reflect an ongoing dialogue between the care provider and the care receiver, focusing on patients' understanding of their health problem and their desired health situation ${ }^{[8]}$. Various dimensions of patient participation are presented in the literature: participation as comprehension (i.e., comprehension of how the own body works, what happens when symptoms occur, etc.), participation as productive communication, participation as confidence, and participation as achieving control ${ }^{[9,10]}$. Patients have reported experiencing participation when they were shown respect ${ }^{[11]}$ and when knowledge was shared with health care professionals ${ }^{[11-14]}$.

Communication in the process of care planning is essential if the outcome of this process is to be patient centered ${ }^{[15,16]}$. Obstruction of patient participation has been identified in relation to lack of competence, insight, or knowledge on the part of staff and significant others' attempts to control the situation ${ }^{[11]}$. A scientific basis, on how all these elements come together to provide a solid evidence base for clinicians' practice aimed at ensuring continuity of care across settings, is lacking. Consequently, while it is possible to find information on some elements of planning, such as patient participation in COCP meetings, it is more difficult to grasp all the interacting parts of this process.

Older, hospitalized patients often have complex health situations involving many different care needs. Their rehabilitation and medical follow-up must be managed outside acute hospital settings. Swedish law states that patients should have the

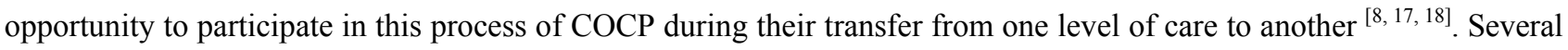
studies in the Swedish context have shown that older adults are often referred from community care to acute care and back $^{[19,20]}$, or between different care levels ${ }^{[21]}$. Thorslund and Wånell report on the widespread occurrence of fragmented care for older adults ${ }^{[22]}$. Lack of information at discharge and lack of continuity of care planning at COCP meetings have been reported by Kihlgren and coworkers ${ }^{[19,23]}$. Because these difficulties are evident in the discharge process, it is important to develop additional knowledge and investigate if, and how, patients are given the opportunity to participate in COCP meetings. Therefore, the aim of the present study was to determine whether patients are given an opportunity to participate in COCP meetings, and if so, what characterizes such meetings.

\section{Methods}

For increased knowledge and a better understanding of the communication pattern in COCP meetings, we chose a descriptive design with a qualitative approach and conducted non-participant observation ${ }^{[24]}$ of the interaction between patients and staff during COCP meetings. The data collected were analyzed using two complementary procedures: firstly, we performed a directed content analysis ${ }^{[25]}$ to develop an intuitive framework ${ }^{[26]}$ concerning the nature and perspective of the interaction, as well as the process. This analysis also included descriptive data of frequencies of utterances at the COCP meetings ${ }^{[27]}$. Secondly, we analyzed the data from a communication perspective using critical discourse analysis $(\mathrm{CDA})^{[28]}$.

\subsection{Setting}

In the Swedish health care system, responsibility for care of older patients is divided between the county council and the local municipality. The primary responsibility lies with the local municipality, and when acute care is required, the county council takes over. When older patients are discharged from acute care and still need medical or nursing care, the responsibility is then transferred to primary health care (PHC), the municipality, or advanced home care (AHC). Primary health care is organized within the county council, but has no responsibility for institutional care. Advanced home care is responsible for advanced care in patients' homes. The AHC team can be organized within the county council or by a 
private entrepreneur, depending on decisions made in the different Swedish county councils ${ }^{[29]}$. The physician responsible for discharge is also responsible for arranging the COCP meeting, and for inviting representatives from other levels of care to the COCP meeting at the hospital ${ }^{[8]}$. The discharging physician has access to the patient's relevant documentation. If the patient is referred to AHC, this physician holds a COCP meeting of his/her own with the patient. The purpose of the COCP meeting is to ensure continuous, quality care for older patients. According to Swedish legislation, the older patient and/or a relative should have the opportunity to participate in this meeting. In practice, physicians often delegate their responsibility to an RN. However, AHC organizations differ with regard to their referral process, which involves several AHC teams to whom physicians send referral letters. A member of the AHC team then contacts the patient at home and registers as responsible care supplier for the patient at a COCP meeting. Since we started the data collection for this study, no significant changes have been made in the process in terms of either regulations or settings.

\subsection{Sample}

During a period of 1 week, all older patients at one hospital ward in one large and one medium city hospital in central Sweden about to be discharged were asked by their ward nurses if they wished to participate in the study. The first six patients $\geq 75$ years old, four women and two men, who agreed to participate were included in the study. Of these patients, four were discharged to their homes. Two were discharged home while awaiting contact from AHC. Observations were made during four COCP meetings at the hospital and two COCP meetings at AHC. In addition to the included patients, health care professionals and relatives attended the COCP meeting, altogether 28 participants (see Table 1).

Table 1. COCP meeting participants

\begin{tabular}{|c|c|c|c|c|c|c|c|}
\hline COCP meeting & RN & Physician & $\begin{array}{l}\text { Physio-/occupa- } \\
\text { tional therapist }\end{array}$ & RN at_PHC & Social officer & Relative/ good friend & Patient \\
\hline \multicolumn{8}{|l|}{ At hospital } \\
\hline A & Yes & - & - & - & Yes & Yes & Yes \\
\hline B & Yes & - & - & - & Yes & Yes & Yes \\
\hline $\mathrm{C}$ & Yes & - & Yes & Yes & Yes & Yes & Yes \\
\hline $\mathrm{D}$ & Yes & Yes & Yes & - & Yes & Yes & Yes \\
\hline \multicolumn{8}{|l|}{$\mathrm{AHC}$ at home } \\
\hline E & Yes & Yes & - & NA* & - & Yes & Yes \\
\hline $\mathrm{F}$ & Yes & Yes & - & NA* & - & Yes & Yes \\
\hline
\end{tabular}

*NA $=$ Not Applicable

\subsection{Data collection}

In connection with the COCP meetings, one of the researchers (T.G.) was invited to the hospital ward when the COCP meetings were due to take place (cases A-D). At AHC (cases E-F), the same procedure was followed, but the meeting was held in the older patient's home.

The data collector (T.G.), an RN, who had previous experience of working in nursing care, had competence in the method and acted as a non-participant observer. The observer took notes on who made an utterance, to whom it was directed, the content of the utterance, and any contextual information that could influence the conversation, such as gestures or body language ${ }^{[24]}$. The observer's focus was on communication and social interaction, as well as content. The content of every utterance was recorded, transcribed into an electronic file, and subsequently checked for correctness by the observer.

\subsection{Data analysis}

Two complementary procedures were used for data analysis: a directed content analysis ${ }^{[25]}$ was performed, with additional descriptive analysis of frequencies of utterances in the COCP meetings ${ }^{[27]}$. Further, the data were analyzed from a communication perspective using $\mathrm{CDA}^{[28]}$. 


\subsubsection{Directed content analysis}

The directed content analysis ${ }^{[25]}$ involved two phases: firstly, the entire dialogue text was read several times and an intuitive framework was developed using inductive method and prior knowledge ${ }^{[26]}$ concerning the nature of the interaction: the perspectives used, and the process. There were two perspectives, the professional view and the patient's view. Four categories were included under process: seek information or give information, and involving the patient or initiated by the patient. In the next phase, the text was divided into meaning units, i.e., text units with a similar meaning. Each meaning unit of the observations was placed into categories using this framework. The researchers independently categorized the meaning units and then discussed differences within the research group until full agreement was reached.

\subsubsection{Critical discourse analysis}

A further analysis was then performed using CDA to study the interactions in the dialogues. During the participant observations, information was recorded on who made an utterance and to whom it was directed. Observation notes regarding the caregivers' body language or eye contact were used to identify and confirm the intended receiver, thereby revealing the direction of the flow of information. Sometimes the receiver of an utterance was understood to be "everyone," in which case the utterance was a rhetorical question or a general statement made to all present. To illustrate the dialogue, a graphic visualization was developed ${ }^{[28]}$.

\subsection{Ethical consideration}

Permission for the study was granted by the Ethics Committee of Linköping County Council (DNR CF 2003/772). The study protocol was approved by the hospital board, which recommended the project and informed the staff on the ward at ward meetings, during which members of staff had the opportunity to ask questions. The same verbal and written information was provided to all staff members. When a COCP meeting was scheduled, a staff member verbally invited the patient to participate in the study. Patients received written information from the staff nurse and agreed to participate before meeting the researcher. The researcher then provided further information about the project and asked for individual consent from all the participants in connection with the COCP meeting.

\subsection{Trustworthiness}

To ensure quality of the findings, methodological considerations have been taken into account related to principles described by Lincoln and Guba ${ }^{[30]}$. To ensure credibility as well as dependability, several steps have been taken, such as purposively selecting the participants, and including different contexts of COCP meetings.

In qualitative studies, the researchers themselves serve as data gatherers and interpreters ${ }^{[31]}$. There is therefore the risk that the observer may have influenced the quality of the data. Hence, the observations were discussed within the research group to increase awareness of possible influences in the data collection and to provide as natural a situation as possible in any subsequent observation. To ensure confirmability of the analysis and categorization of data, discussions between the researchers were taken throughout the whole process of analysis.

\section{Results}

To give a comprehensive picture, our findings are presented in the following order: first, we present two cases, one from each kind of setting: case COCP-A is from a meeting in the hospital setting, while case COCP-E is from a meeting in the AHC setting, i.e., the patient's home. Within the report for each case, a table (COCP-A: Table 2, and COCP-E: Table 4) illustrates selected examples of meaning units, classified using the categories covering the nature of the interaction. These are examples of the analysis presented verbatim from the field notes. The table shows whether the meaning units were categorized according to perspective, i.e., the professional's view or the patient's view, or whether the content of the meaning unit represents a process, i.e., (a) searching for information or giving information, and (b) involving the patient or initiated by the patient. Each case description concludes with a summary table that displays the frequency of meaning units for the two cases, COCP-A and COCP-E (see Table 3 and Table 5). 
Table 2. Case COCP-A dialogue: Examples (17/69) of meaning units classified by nature of interaction. Some meaning units are counted in two columns, e.g. professional view and give info or searching info and initiated by the patient.

\begin{tabular}{|c|c|c|c|c|c|c|}
\hline \multirow[b]{2}{*}{ Meaning units* } & \multicolumn{2}{|c|}{ Perspective ** } & \multicolumn{4}{|c|}{ Process $* *$} \\
\hline & $\begin{array}{l}\text { Professional } \\
\text { view }\end{array}$ & $\begin{array}{l}\text { Patient } \\
\text { view }\end{array}$ & Search info & $\begin{array}{l}\text { Give } \\
\text { info }\end{array}$ & $\begin{array}{l}\text { Involving } \\
\text { patient }\end{array}$ & $\begin{array}{l}\text { Initiated } \\
\text { by patient }\end{array}$ \\
\hline RN: -NN has got a stroke 11 days ago. & $\mathrm{C}$ & & & $\mathrm{C}$ & & \\
\hline $\begin{array}{l}\text { The consequences are weakness in the right side } \\
\text { and paralysis in the face. }\end{array}$ & $\mathrm{C}$ & & & $\mathrm{C}$ & & \\
\hline She takes care of herself on the ward. & $\mathrm{C}$ & & & $\mathrm{C}$ & & \\
\hline NN sees slightly doublet & $\mathrm{C}$ & & & $\mathrm{C}$ & & \\
\hline and has difficulties to see straight ahead & $\mathrm{C}$ & & & $\mathrm{C}$ & & \\
\hline SO: -NN wants a security alarm installed. & $\mathrm{C}$ & & & $\mathrm{C}$ & & \\
\hline RN: NN will bring a walker at home & $\mathrm{C}$ & & & $\mathrm{C}$ & & \\
\hline $\begin{array}{l}\text { SO: -I promise to check with the housekeeper so } \\
\text { the elevator will work }\end{array}$ & $\mathrm{C}$ & & & $\mathrm{C}$ & & \\
\hline $\begin{array}{l}\text { RN: The patient will also borrow a chair from } \\
\text { the hospital to use in the shower. }\end{array}$ & $\mathrm{C}$ & & & $\mathrm{C}$ & & \\
\hline $\begin{array}{l}\text { RN: We will send prescription note with } \\
\text { medications. It might include antibiotics. }\end{array}$ & & & & $\mathrm{C}$ & & \\
\hline $\begin{array}{l}\text { SO: You can try a couple of days and find out } \\
\text { what kind of help you want. }\end{array}$ & & & & $\mathrm{C}$ & & \\
\hline $\begin{array}{l}\text { You can get help with shower in connection } \\
\text { with cleaning help. }\end{array}$ & $\mathrm{C}$ & & & $\mathrm{C}$ & & \\
\hline $\mathrm{P}:$ Who is coming? & & & $\mathrm{P}$ & & & $P$ \\
\hline SO: You will know them. & & & & $\mathrm{C}$ & & \\
\hline R: Can we also ask for transportation service? & & & $\mathrm{R}$ & & & $\mathrm{R}$ \\
\hline $\begin{array}{l}\text { SO: Yes, it can be arranged. When I arrive on } \\
\text { Thursday, we'll take care of that. }\end{array}$ & & & & $\mathrm{C}$ & & \\
\hline
\end{tabular}

*Column 1: RN is Reg. Nurse of the ward, SO is social officer, $\mathrm{P}$ is patient and $\mathrm{R}$ is relative (daughter). ${ }^{* *}$ Columns 2-7: $\mathrm{P}$ is for patient, $\mathrm{R}$ for relative and $\mathrm{C}$ for care supplier

A graphic visualization, derived from the CDA, of these sample meaning units is presented next, to show the interaction in the dialogue (COCP-A: Figure 1, COCP-E: Figure 2, all COCP meetings: Figure 3). The introduction by the nurse is not marked. In Figures 1-3, the professional staffs are placed on the left, and the relatives and patients on the right. The first column on the left is for the nurse who took charge and led the COCP meeting, followed by the municipal representative. This is followed, in the middle, by "everyone" (or no-one), with the patient's relatives followed by the patient him/herself on the right. The arrows are in chronological order starting at the beginning of the COCP meeting, each arrow representing an utterance.

Tables 3-5 show the dialogues with examples. Table 6 is a summary table reflecting the nature of interaction in all COCP dialogues. Finally in this section, we present a graphic visualization of each of the six COCP dialogues (COCP-A-E), which was derived using CDA. Each arrow in this depiction is used to represent one utterance as well as the direction of the information flow. This conceptual representation of the dialogues allows some preliminary comparison across the six COCP meetings.

\subsection{Case COCP-A}

Participants in the COCP-A dialogue were the patient (P), two relatives (daughters) (Ds), the ward nurse (RN), and the municipal social officer (SO). Table 2 contains an excerpt from the dialogue and shows how it was categorized. 
Figure 1 visualizes the dialogue, showing that most utterances were directed at "everyone" or no-one in particular. The arrows show who made an utterance and who was understood to be the receiver of the utterance. This visualization shows the interaction between all participants in a general mode.

$\begin{array}{llll}\text { Reg. Nurse } & \text { Social officer } & \text { Everyone } & \text { Relative }\end{array}$

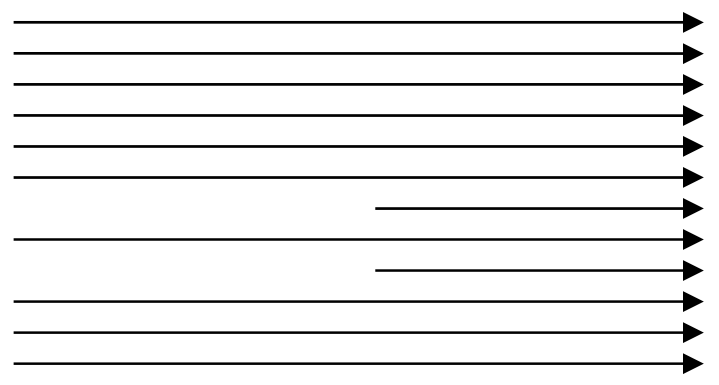

Figure 1. Visualisations of the interaction in the case COCP-A dialogue.

Table 3 shows a summary of the nature of the interaction for the 69 utterances in the COCP-A dialogue, categorized as 105 meaning units.

Table 3. Case COCP-A dialogue: Summary of nature of interaction displayed by source of utterance, frequency and percent ( $n=69$ meaning units). Some meaning units are counted in two columns, e.g. professional view and give information.

\begin{tabular}{|c|c|c|c|c|c|c|c|c|}
\hline \multirow{2}{*}{$\begin{array}{l}\text { Classified meaning } \\
\text { units: by source of } \\
\text { utterance, number and } \\
\text { percent }\end{array}$} & \multicolumn{3}{|c|}{ Perspective } & \multicolumn{5}{|c|}{ Process } \\
\hline & $\begin{array}{l}\text { Professional } \\
\text { view }\end{array}$ & $\begin{array}{l}\text { Patient } \\
\text { view }\end{array}$ & Total & $\begin{array}{l}\text { Search } \\
\text { info }\end{array}$ & $\begin{array}{l}\text { Give } \\
\text { info }\end{array}$ & $\begin{array}{l}\text { Involving } \\
\text { patient }\end{array}$ & $\begin{array}{l}\text { Initiated by } \\
\text { patient }\end{array}$ & Total \\
\hline Caregiver & & - & 27 & 3 & 47 & 3 & - & 53 \\
\hline Relative & 27 & 2 & 2 & 4 & 4 & - & 1 & 9 \\
\hline Patient & & 2 & 2 & 2 & 7 & 2 & 1 & 12 \\
\hline Total number & 27 & 4 & 31 & 9 & 58 & 5 & 2 & 74 \\
\hline Total percent & 87 & 13 & 100 & 12 & 78 & 7 & 3 & 100 \\
\hline
\end{tabular}

\section{Summary of case COCP-A}

The case COCP-A dialogue can be described as having fewer than average (for a hospital setting in our study) utterances $(\mathrm{n}=69, \mathrm{~m}=87$, with 105 categorized meaning units) and appears to be less information intensive, i.e., not having many meaning units concerning the patient's view or situation. In terms of the information framework and the nature of the interaction, the professional perspective dominated, amounting to $87 \%$ (27/31) of the meaning units. Regarding the process of information sharing, information giving was found in $78 \%$ of the meaning units (58/74), while searching for information was relatively infrequent, amounting to $12 \%(9 / 74)$. The other part of the process aspect, involving the patient 
and initiated by the patient, only occurred in 7\% (five instances) and 3\% (two instances), respectively, of utterances in this dialogue.

Most of the conversation in case COCP-A dealt with administrative issues, e.g., what should be done and by whom. The $\mathrm{RN}$ opened the meeting by mentioning the need to have a security alarm installed, an available walker, a key to the apartment, and food distribution before the patient's need for help with showering was noted. Only a few questions were addressed to the patient concerning her view of her situation. No statements were made by the patient concerning her own capacity for self-care. The RN drew up the agenda for, and led, the conversation.

The patient's problems were dizziness, diplopia, and the associated risk of falling. The patient understood these to be problems. Solutions provided were help with some daily activities, e.g., showering.

\subsection{Case COCP-E}

Participants in the COCP-E meeting were the patient (P), a relative (friend) $(\mathrm{R})$, the physician $(\mathrm{Ph})$, and the nurse from AHC (RN). Table 4 shows a summary of the nature of the interaction for the 335 utterances made in the COCP-E dialogue.

Table 4. From case COCP-E dialogue: Examples (14/335) of meaning units classified by nature of interaction. Some meaning units are counted in two columns, e.g. questions that seek to involve the patient.

\begin{tabular}{|c|c|c|c|c|c|c|}
\hline \multirow[b]{2}{*}{ Meaning units* } & \multicolumn{2}{|l|}{ Perspective** } & \multicolumn{4}{|c|}{ Process** } \\
\hline & $\begin{array}{l}\text { Professional } \\
\text { view }\end{array}$ & $\begin{array}{l}\text { Patient } \\
\text { view }\end{array}$ & $\begin{array}{l}\text { Search } \\
\text { info }\end{array}$ & $\begin{array}{l}\text { Give } \\
\text { info }\end{array}$ & $\begin{array}{l}\text { Involving } \\
\text { patient }\end{array}$ & $\begin{array}{l}\text { Initiated } \\
\text { by patient }\end{array}$ \\
\hline $\begin{array}{l}\text { Ph: First NN, I would like to ask you..........N are } \\
\text { you called } N \text { or } X ?\end{array}$ & & & $\mathrm{C}$ & & $\mathrm{C}$ & \\
\hline P: $N$ & & & & $\mathrm{P}$ & & \\
\hline $\begin{array}{l}\mathrm{Ph} \text { : Well N. What information have you got about } \\
\text { your disease? }\end{array}$ & & & $\mathrm{C}$ & & $\mathrm{C}$ & \\
\hline $\begin{array}{l}\text { P: On the hospital. But I have been there twice } \\
\text { before. }\end{array}$ & & & & $\mathrm{P}$ & $\mathrm{P}$ & \\
\hline But they don't know what it is. & & & & $\mathrm{P}$ & $\mathrm{P}$ & \\
\hline $\begin{array}{l}\text { I fell on the floor but couldn't get up. I came to the } \\
\text { hospital. }\end{array}$ & & & & $\mathrm{P}$ & $\mathrm{P}$ & \\
\hline $\mathrm{Ph}$ : Okey. What have they told you then? & & & $\mathrm{C}$ & & $\mathrm{C}$ & \\
\hline $\begin{array}{l}\text { P: They have said they don't know what kind of } \\
\text { disease it is. }\end{array}$ & & & & $\mathrm{P}$ & $\mathrm{P}$ & \\
\hline $\begin{array}{l}\text { Ph: Okey. I could see in the documentation that } \\
\text { you don't want to be informed. }\end{array}$ & & & $\mathrm{C}$ & & & \\
\hline $\begin{array}{l}\text { P: Well... I haven't heard. They cannot tell me } \\
\text { what disease I have got. Of course I would like to } \\
\text { know }\end{array}$ & & & & $\mathrm{P}$ & $\mathrm{P}$ & \\
\hline $\mathrm{Ph}$ : You want to be informed. & & & $\mathrm{C}$ & & & \\
\hline P: Yes, I want. But they don't know. & & $\mathrm{P}$ & & $\mathrm{P}$ & & \\
\hline $\begin{array}{l}\mathrm{Ph} \text { : In the stomach there is a.....gland called } \\
\text { pancreas and it produces bile so you could digest } \\
\text { the food. And it takes care of the blood sugar }\end{array}$ & $\mathrm{C}$ & & & $\mathrm{C}$ & & \\
\hline $\mathrm{Ph}$ : Inside you they have found a tumour there. & $\mathrm{C}$ & & & $\mathrm{C}$ & & \\
\hline P: Aha, yes & & & & & & \\
\hline
\end{tabular}

Column 1: $\mathrm{Ph}$ is physician and $\mathrm{P}$ is patient. ** Columns 2-7: $\mathrm{P}$ is for patient and $\mathrm{C}$ for care supplier

Figure 2 visualizes the dialogue, showing utterances involving the patient and information given by the patient. 


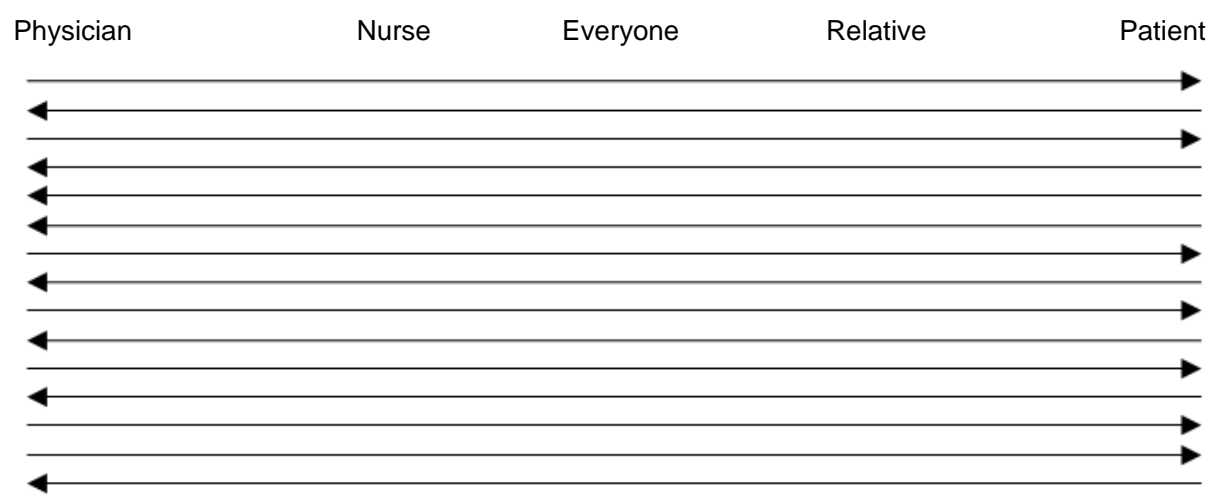

Figure 2. Visualisations of the interaction in the case COCP- E dialogue.

Table 5 summarizes the nature of the interaction, by source of utterance, frequency, and percent ( $\mathrm{n}=335 \mathrm{meaning}$ units).

Table 5. Case COCP-E dialogue: Summary of nature of interaction displayed by source of utterance, frequency and percent ( $n=341$ meaning units). Some meaning units are counted in two columns, e.g. professional view and give information or searching info and involving patient.

\begin{tabular}{|c|c|c|c|c|c|c|c|c|}
\hline \multirow{2}{*}{$\begin{array}{l}\text { Classified meaning } \\
\text { units: by source of } \\
\text { utterance, number } \\
\text { and percent }\end{array}$} & \multicolumn{3}{|l|}{ Perspective } & \multicolumn{5}{|l|}{ Process } \\
\hline & $\begin{array}{l}\text { Professional } \\
\text { view }\end{array}$ & $\begin{array}{l}\text { Patient } \\
\text { view }\end{array}$ & Total & $\begin{array}{l}\text { Search } \\
\text { info }\end{array}$ & Give info & $\begin{array}{l}\text { Involving } \\
\text { patient }\end{array}$ & $\begin{array}{l}\text { Initiated by } \\
\text { patient }\end{array}$ & Total \\
\hline Caregiver & 35 & 1 & 36 & 34 & 119 & 36 & - & 189 \\
\hline Relative & 1 & 8 & 9 & 1 & 27 & - & 1 & 29 \\
\hline Patient & 2 & 40 & 42 & 7 & 107 & - & 9 & 123 \\
\hline Total number & 38 & 49 & 87 & 42 & 253 & 36 & 10 & 341 \\
\hline Total percent & 46 & 54 & 100 & 12 & 74 & 11 & 3 & 100 \\
\hline
\end{tabular}

\section{Summary of case COCP-E}

The COCP-E dialogue can be described as very information intensive, showing the largest number of meaning units $(n=335)$ of all six COCP dialogues (range 34-335), its number also being above the average, 325, for the two AHC dialogues. In this AHC dialogue, unlike the four hospital setting dialogues, the patient/relative view is predominant, with the patient/relative perspective in place more than half of the time $(55 \%, 47 / 85)$.

Similar to the other five COCP dialogues, providing information was the predominant process noted in case COCP-E, where it comprised well over $80 \%$ of the meaning units COCP related to process.

There was "patient involvement," as part of the interaction process in this dialogue, of $11 \%$, while interaction "initiated by the patient" amounted to only $3 \%$.

In this dialogue, the schedule shows many utterances involving giving information to the patient and information given by the patient. The type of questions posed by the staff required more than yes/no answers from the patient. There was a real dialogue reflecting a sincere interest in answers given. Questions were asked, not to confirm professional statements, but to gain information regarding the patient's expectations and knowledge about the actual situation. The topics covered were self-awareness, autonomy, social relations, symptoms, context, and agreement. The patient was the informant, even though he had not drawn up the agenda and was not the leader of the conversation. 
Table 6. COCP-dialogues for all patients by setting, classified meaning units, source of information summarized by frequencies and percent (net number of meaning units $n=1007$. Some meaning units are counted in two columns, e.g. professional view and give information or searching info and involving patient.

\begin{tabular}{|c|c|c|c|c|c|c|c|c|}
\hline \multirow{2}{*}{$\begin{array}{l}\text { Classified meaning } \\
\text { units by setting, } \\
\text { source of utterance, } \\
\text { number and } \\
\text { percent }\end{array}$} & \multicolumn{3}{|l|}{ Perspective } & \multicolumn{5}{|l|}{ Process } \\
\hline & $\begin{array}{l}\text { Professional } \\
\text { view } \\
\text { No }(\%)\end{array}$ & $\begin{array}{l}\text { Patent } \\
\text { view } \\
\text { No (\%) }\end{array}$ & $\begin{array}{l}\text { Total } \\
\text { No (\%) }\end{array}$ & $\begin{array}{l}\text { Search } \\
\text { info } \\
\text { No (\%) }\end{array}$ & $\begin{array}{l}\text { Give info } \\
\text { No (\%) }\end{array}$ & $\begin{array}{l}\text { Involving } \\
\text { patient } \\
\text { No (\%) }\end{array}$ & $\begin{array}{l}\text { Initiated } \\
\text { by patient } \\
\text { No }(\%)\end{array}$ & $\begin{array}{l}\text { Total } \\
\text { No (\%) }\end{array}$ \\
\hline \multicolumn{9}{|l|}{ At Hospital } \\
\hline A: Caregiver & 27 & - & 27 & 3 & 47 & 3 & - & 53 \\
\hline Relative & - & 2 & 2 & 4 & 4 & & 1 & 9 \\
\hline Patient & - & 2 & 2 & 2 & 7 & 2 & 1 & 12 \\
\hline A: Total $(n=69)$ & $27(87)$ & $4(13)$ & $31(100)$ & $9(12)$ & $58(78)$ & $5(7)$ & $2(3)$ & $74(100)$ \\
\hline B: Caregiver & 20 & 1 & 21 & 40 & 70 & 28 & 1 & 139 \\
\hline Relative & 1 & 10 & 11 & 5 & 35 & & 1 & 41 \\
\hline Patient & - & - & - & 0 & 35 & 1 & - & 36 \\
\hline B: Total $(n=186)$ & $21(66)$ & $11(34)$ & $32(100)$ & $45(21)$ & $140(65)$ & $29(13)$ & $2(1)$ & $216(100)$ \\
\hline C: Caregiver & 12 & 1 & 13 & 12 & 20 & 4 & & 36 \\
\hline Relative & - & 2 & 2 & 3 & 15 & 1 & 1 & 20 \\
\hline Patient & - & 5 & 5 & 0 & 10 & 1 & - & 11 \\
\hline C: Total $(n=60)$ & $12(60)$ & $8(40)$ & $20(100)$ & $15(25)$ & $45(75)$ & $6(10)$ & $1(2)$ & $67(100)$ \\
\hline D: Caregiver & 10 & - & 10 & 3 & 17 & 3 & - & 23 \\
\hline Relative & 1 & 2 & 3 & 0 & 5 & - & 2 & 7 \\
\hline Patient & - & 3 & 3 & 0 & 8 & - & 2 & 10 \\
\hline D: Total $(n=34)$ & $11(69)$ & $5(31)$ & $16(100)$ & $3(7,5)$ & $30(75)$ & $3(7,5)$ & $4(10)$ & $40(100)$ \\
\hline Total: A-D (n=349) & $71(72)$ & $28(28)$ & $99(100)$ & $72(18)$ & $273(69)$ & $43(11)$ & $9(2)$ & $397(100)$ \\
\hline Mean A-D & & & & & & & & 327 \\
\hline Total No. & 18 & 7 & 25 & 18 & 68 & 11 & 2 & 99 \\
\hline Caregiver & 17 & $<1$ & 18 & 15 & 39 & $<10$ & $>0$ & 63 \\
\hline Relative & 1 & 4 & $>4$ & 3 & 15 & $>0$ & 1 & 19 \\
\hline Patient & - & $>2$ & $>2$ & $<1$ & 15 & $<1$ & $<1$ & 17 \\
\hline \multicolumn{9}{|l|}{ At AHC } \\
\hline E: Caregiver & 35 & 1 & 36 & 34 & 119 & 36 & - & 189 \\
\hline Relative & 1 & 8 & 9 & 1 & 27 & - & 1 & 29 \\
\hline Patient & 2 & 40 & 42 & 7 & 107 & - & 9 & 123 \\
\hline $\mathrm{E}: \operatorname{Total}(\mathrm{n}=335)$ & $38(44)$ & $49(56)$ & $87(100)$ & $42(12)$ & $253(74)$ & $36(11)$ & $10(3)$ & $341(100)$ \\
\hline F: Caregiver & 24 & 20 & 44 & 71 & 121 & 57 & - & 249 \\
\hline Relative & - & 10 & 10 & 8 & 44 & 2 & - & 54 \\
\hline Patient & 1 & 26 & 27 & 1 & 78 & 86 & 11 & 176 \\
\hline F: Total $(n=320)$ & $25(31)$ & $56(69)$ & $81(100)$ & $80(17)$ & $243(51)$ & $145(30)$ & $11(2)$ & $479(100)$ \\
\hline Total: $\mathrm{E}-\mathrm{F}(\mathrm{n}=655)$ & $63(38)$ & $103(62)$ & $166(100)$ & $122(15)$ & $496(61)$ & 181(22) & $21(3)$ & $820(100)$ \\
\hline Mean E-F & & & & & & & & 87 \\
\hline Total No. & 32 & 52 & 83 & 61 & 248 & $>90$ & $>10$ & 410 \\
\hline Caregiver & 30 & 10 & 40 & $>52$ & 120 & $>46$ & - & 219 \\
\hline Relative & $<1$ & 9 & 9 & $>4$ & $>35$ & 1 & $<1$ & $<42$ \\
\hline Patient & $<2$ & 33 & 34 & 4 & $>92$ & 43 & 10 & $<150$ \\
\hline
\end{tabular}

The problems understood by the patient in case COCP-E were stomach pain and digestion problems. The physician clarified that the problems understood by the staff and the problems understood by the patient were adjusted in the documentation, often by asking the patient about his experiences and knowledge about the illness. Then he allowed the patient to elaborate on how this health problem might affect his everyday life, and what different kinds of support he needed. The RN took part in the dialogue late in the session, in relation to practical nursing issues. Most of the professional 
view was presented after permission was given by the patient to the professionals to explain the disease he was suffering from. Without stepping back from their professional point of view, the physician and $\mathrm{RN}$ managed to interweave the patient's own understanding of his problem with information on how he could be relieved from pain and suffering.

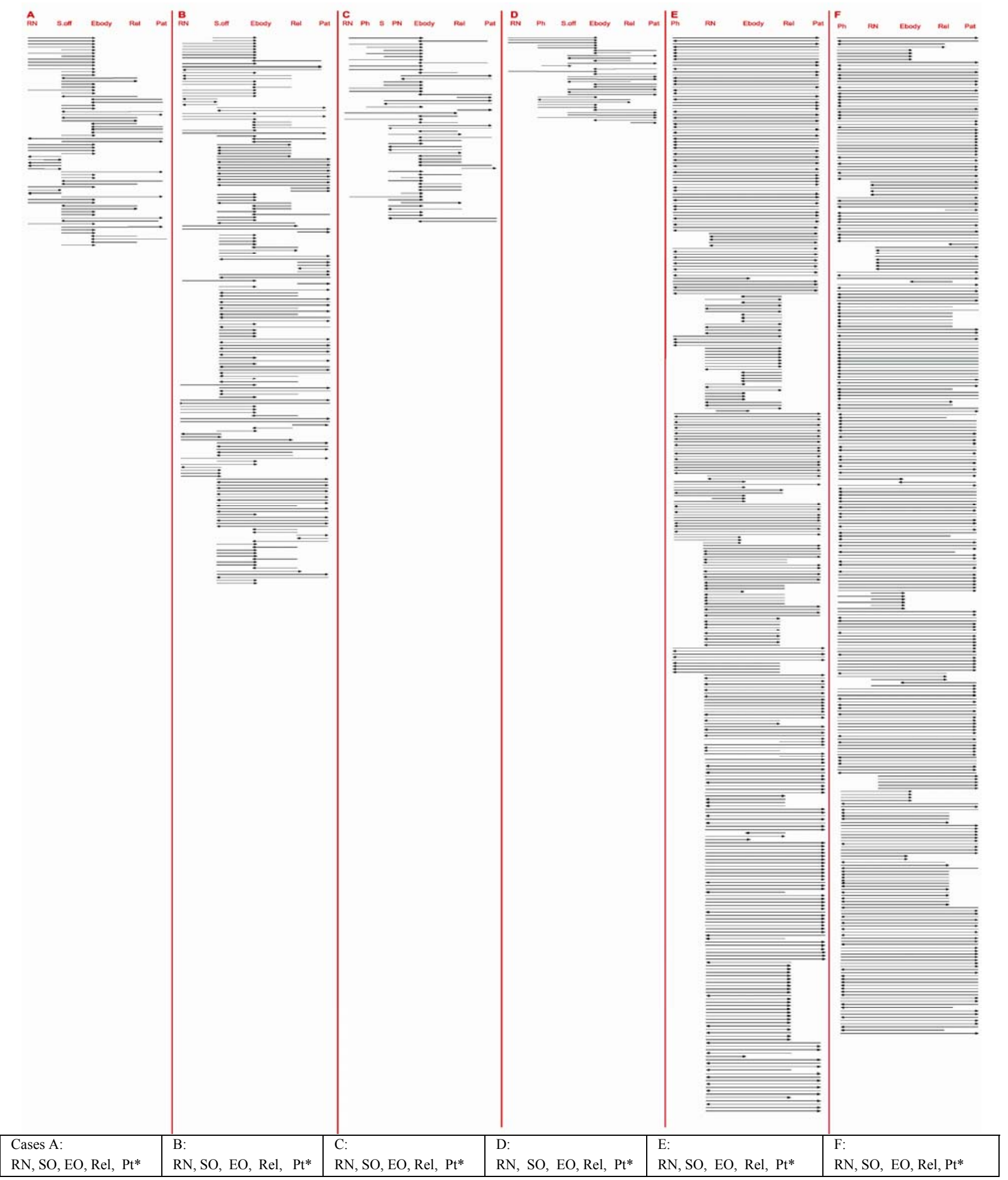

Figure 3. Visualisation of the interaction in the COCP-dialogues for all six patients, with number of meaning units and time used in minutes. $*$ RN=Reg Nurse, $\mathrm{SO}=$ Social officer, $\mathrm{EO}=$ Everyone, Rel=Relative, $\mathrm{Pt}=$ Patient 


\subsection{Presentation of all coordinated care planning dialogues}

On the whole, the four hospital-based COCP dialogues were much briefer than the two AHC dialogues. These COCP dialogues consisted of the fewest unduplicated meaning units (COCP-A: 69, COCP-B: 186, COCP-C: 60, and COCP-D: 34), whereas the AHC dialogues consisted of 335 (COCP-E) and 314 (COCP-F) meaning units, respectively. A graphic visualization of all the interactions, organized in the same way as the two cases presented above, is shown in Figure 3, and the number of times that the different views became apparent in all COCP meetings are presented in Table 6 .

The analyses show that each kind of COCP meeting had a similar pattern of interaction within their respective setting (see Figure 3). In the COCP meetings at the hospital (cases COCP-A-D), the focus seemed to be on presenting information. The utterances were primarily aimed at everyone present and no real dialogue was seen, in that many utterances were rhetorical, without any expectation of relevant answers that would give a deeper understanding of the patient's wishes or everyday life situation. On the other hand, in the COCP meetings with AHC (cases COCP-E-F), a different approach was observed. During these, there were many instances of dialogue between the physician or other staff, and the patient. The AHC staff skillfully placed the patient at the center and put him/her in charge of care planning and of determining what expectations were realistic.

\subsection{Summary of results}

The number of utterances in the two settings differed. The four COCP dialogues at the hospital contained 349 utterances in total, with a mean of 87 and a range of 34-186 utterances per dialogue, whereas the two COCP dialogues with AHC contained 655 utterances in total, with a mean of 327 and a range of 320-335 per dialogue.

The COCP dialogues at the hospital contained 397 categorized meaning units, with a mean of 99 and a range of 40-216, while the two AHC dialogues contained 820 meaning units, with a mean of 410 and a range of 341-479 (Table 6).

The perspective of the interaction was predominantly professional in all the hospital-based COCP dialogues, as shown in Table 6. The professionals tended to begin the dialogue with a summary, to aid the patient's understanding of the problem. Consequently, they started by focusing on giving information about the patient's health status and problems and how to deal with them, all of which was presented from a professional point of view. In these dialogues, the share of meaning units expressing a professional view comprised $72 \%$ (range $60 \%-87 \%$; mean 18 per dialogue) of all perspective-related meaning units. This was more than double the share of meaning units expressing a patient view $(28 \%$; range $13 \%-40 \%$; mean 7 per dialogue).

In the AHC dialogues conducted in the patients' homes, however, the opposite picture was found for perspective, showing the importance of the patient's perspective. The share of meaning units expressing a professional perspective comprised $38 \%$ of all perspective meaning units (range $31 \%-44 \%$; mean 32 per dialogue), versus $62 \%$ for the patient's perspective (range 56\%-69\%; mean 52 per dialogue, which is over seven times more than the mean in the COCP dialogues at the hospital).

With AHC, the COCP dialogue was started by asking the patient about his/her knowledge about his/her illness and encouraging him/her to describe living with the illness. Immediately, a different atmosphere was created. Using this approach, the professionals showed that it is the patient who knows and the staff that need to acquire that knowledge.

Our findings visualize the difference in perspective between the two settings for the six dialogues we studied.

The nature of the interaction as process consisted of four parts, of which "searching for information" showed the greatest differences between the two settings. Twenty percent of the process meaning units in COCP meetings at the hospital were comprised of information seeking meaning units, with a mean of 18 per dialogue, compared to $15 \%$ of all process meaning units at the AHC, with a mean of 61 per dialogue, i.e., more than three times higher. 
Of all the process meaning units, "giving information" comprised $79 \%$, with a mean of 68 per dialogue, in the COCP meetings at the hospital, compared to $61 \%$, with a mean of 248 meaning units per AHC dialogue, i.e., almost four times as many.

"Involving the patient" made up less of the process in the COCP dialogues at the hospital, where it comprised $11 \%$ of all process meaning units with a mean of eleven per dialogue, while the same figures for AHC were $22 \%$ of all process meaning units and a mean of 90 per dialogue, i.e., eight times higher.

The fourth part of the process, "initiated by the patient" showed comparable figures in the two settings, comprising a low $2 \%$ and $3 \%$ at the hospital and $\mathrm{AHC}$, respectively, with a mean of two per dialogue in the COCP dialogues at the hospital and ten per dialogue for the AHC dialogues.

\section{Discussion}

The focus of this qualitative study was to determine whether patients are given an opportunity to participate in the planning of their care, and if they are, what characterizes these COCP meetings. Patients' participation in their own care is important, yet there is a lack of literature on patient participation in COCP meetings.

The main finding indicates a general lack of patient participation in COCP meetings at the hospital. The dialogues appeared to be less information intensive, and a professional perspective dominated the interaction. The meetings started with a summary of the problem, focusing on giving information about health status, and problems and how to deal with them, all from a professional point of view. Only a few questions were addressed to patients, and few asked for their views on their situation. In COCP meetings in AHC, by contrast, the patient perspective predominated. From the outset, it was evident who the informant was (the patient) and what perspective predominated (the patient's) (see Tables 2 and 4). The AHC dialogues began differently, by asking about the patient's knowledge of and feelings about his/her illness. According to Virtanen and coworkers, the initiation and progression of the dialogue is basic to creating a dialogue that involves the patient ${ }^{[32]}$.

Looking at the progression of the dialogues in the COCP meetings at the hospital and with AHC, the focus of the hospital COCP meetings seemed to be on the patient's environment, i.e., more on practical questions than on the patient's experiences of his/her own needs. The progression of the dialogues at the AHC was based on patients' assessments of their own knowledge and abilities, and in this way patients were encouraged to participate in choosing the topic of the discourse. This gave them the opportunity to reflect on their situation in relation to a particular topic, and they could bring issues of importance to themselves up for discussion. Furthermore, by giving advice and feedback, the nurses and physician showed their genuine interest during the dialogue. All this together seemed to create a dialogue that involved the patient in the process, which is similar to the findings reported by Virtanen and coworkers ${ }^{[32]}$.

Several studies have shown that the patient's role as an equal and competent participant in dialogue is important in helping patients get involved, e.g., in planning their own care ${ }^{[2,32]}$. Hedberg showed how professionals are in a position of power and influence in relation to the patient ${ }^{[33]}$. In a process such as care planning, the patient is being evaluated in some sense. Thus, in this process, the patient can be subordinated by professionals or choose a subordinated position him/herself in relation to "the experts". The persons steering this process often play a central role, while subordinated persons in the interaction can be positioned as non-persons. This could also be seen as an "I-you-distant provider dominance" in the interaction between the patient and the professional. This is characterized by the professional being expected to take on the role of assessing the relevance of problems, and finding a solution for them, and the patient being expected to follow these suggestions ${ }^{[34]}$. Perhaps in COCP, the professional position is underlined by the context. The RN might act on delegation of responsibility by other professionals, such as doctors, physiotherapists, and occupational therapists. However, one consequence of this limited patient participation in COPC is that not all the patient's needs are assessed and met, and, consequently, that the care is not patient centered ${ }^{[35]}$. In a Danish study, one-third of patients' problems were not known to 
the nursing staff in the hospital context ${ }^{[36]}$. Discrepancies between patients' and professionals' perspectives have also been explored in other care contexts ${ }^{[34,37]}$.

Shared power was observed in the AHC dialogues when patients and nurses actively participated in choosing the topic of discussion and when patients were given the opportunity to get involved in the dialogue, which also is in line with Virtanen and coworkers' findings ${ }^{[32]}$. This could be seen as "I-you-sorted mutuality," which has been described as a shared knowledge between the patient and the professional ${ }^{[34]}$ about the problems, based on "cocreating person-specific knowledge," i.e., a concrete insight into each particular person's reaction to living with illness ${ }^{[38]}$. The context of AHC was the patient's home, which creates a different patient position. The patient was the host and the informant, thus being an equal to the professionals. The RN, too, can have a more independent and "self-made" role in this context.

Professionals often resort to a biomedical approach, focusing on disease and symptoms, rather than being open to difficulties experienced by different patients and taking a life-oriented perspective ${ }^{[38,39]}$. This is in line with results of a systematic review of older people's views of hospital discharge, in which the need for a "life-planning" perspective before, during, and after hospital discharge was pointed out ${ }^{[2]}$. This perspective allows older people to re-evaluate how to manage their life, and not just to focus on physical and safety needs, functional capacity, and risk minimization, which are often prioritized by the professionals ${ }^{[2]}$. However, further studies are needed to explore how to increase older people's participation in their own care and particularly in COCP. There is also a need for studies with experimental and evaluative designs to gain more evidence-based knowledge about older people's participation in COCP.

\subsection{Limitations of the study}

Non-participant observation was chosen due to the contexts studied ${ }^{[40]}$. The observer effect is a possible limitation, because the observer's presence during the meetings may have influenced the conversations ${ }^{[24]}$. The observer was well aware of this risk, and tried to maintain a non-influential position throughout the observations. A combination of methods was used to give a deeper understanding of the phenomenon and the process ${ }^{[41]}$. The same researcher who wrote the field notes for the present study also took part in the data analyses.. As the data were descriptive, we deemed it important to choose methods of both a deductive and an inductive, interpretative nature.

The researcher's responsibility is to ensure that interpretations are trustworthy ${ }^{[42]}$ and independent assessments were made to support the credibility of the interpretation. This result is based on six patients and their relatives and related staff, altogether 28 participants. This could be seen as appropriate in a qualitative study. However, generalizations cannot be made and conclusions should be drawn with caution.

\subsection{Conclusion}

The main finding of this qualitative study is that the degree of patients' participation in COCP meetings may differ across settings. How the conversations started seemed to be of great importance in this respect. Questions that may arise concern whether caregivers are able to spend enough time, and whether patients are given enough time, to reflect over future needs outside the hospital or whether a solution to practical and other issues has to be found. The context in which the COCP meetings were carried out was different in these two settings. It is reasonable to believe that the patient is more vulnerable and has more barriers to participation in the care context at the hospital than in the context of his/her own home. In addition, there is a shortage of time in health care today, and financial issues are also pressing. There may therefore be a risk that professional solutions to patient care are prioritized over efforts to find solutions that incorporate both the patient's experiences and professional knowledge. The findings of this study can be seen as a base for further research. Studies using quantitative methods are needed to evaluate statistical differences between groups and allow generalizations.

\section{References}

[1] McKeown F. The experiences of older people on discharge from hospital following assessment by the public health nurse. J Clin Nurs. 2007; 16: 469-476. http://dx.doi.org/10.1111/j.1365-2702.2006.01556.x 
[2] Fisher M, Qureshi H, Hardyman W, Homewood J. Using qualitative research in systematic reviews: Older people's views of hospital discharge. How knowledge works in social care report 9. London: Social Care Institute for Excellence, 2006.

[3] Waters K, Allsopp D, Davidson I, Dennis A. Sources of support for older people after discharge from hospital: 10 years on. J Adv Nurs. 2001; 33: 575-582. PMid:11298193 http://dx.doi.org/10.1046/j.1365-2648.2001.01702.x

[4] Armitage S, Kavanagh K. Consumer -oriented outcomes in discharge planning: a pilot study. J Clin Nurs. 1998 ; 7 : 67-74. PMid:9510710 http://dx.doi.org/10.1046/j.1365-2702.1998.00136.x

[5] Mistiaen P, Duijnhouwer E, Wijkel D, de Bont M, Veeger A. The problems of elderly people at home one week after discharge from an acute care setting. J Adv Nurs. 1997; 25: 1233-1240. PMid:9181422 http://dx.doi.org/10.1046/j.1365-2648.1997.19970251233.x

[6] Waters K. Discharge planning: an exploratory study of the process of discharge planning on geriatric wards. J Adv Nurs. 1987; 12: 71-83. PMid:3643943 http://dx.doi.org/10.1111/j.1365-2648.1987.tb01305.x

[7] Waters K. Outcomes of discharge from hospital for elderly people. J Adv Nurs. 1987; 12: 347-355. PMid:3036922 http://dx.doi.org/10.1111/j.1365-2648.1987.tb01341.x

[8] The National Board of Health and Welfare. Cooperation by registration and discharging patients in medical care. SOSFS 2005:27. Stockholm, 2005. (In Swedish: Socialstyrelsens föreskrifter och allmänna råd. Samverkan vid in och utskrivning av patienter i sluten vård. SOSFS 2005:27. Stockholm. Socialstyrelsen).

[9] Eldh AC. Patient participation - what it is and what it is not. PhD thesis. Örebro University, Örebro, Sweden, 2006.

[10] Eldh AC, Ehnfors M, Ekman I. The phenomena of participation and non-participation in health care-experiences of patients attending a nurse-led clinic for chronic heart failure. Eur J Cardiovasc Nurs. 2004; 3: 239-246. PMid:15350234 http://dx.doi.org/10.1016/j.ejcnurse.2004.05.001

[11] Sahlsten JMM, Larsson IE, Lindencrona CSC, Plos KAE. Hindrance for patient participation. Scand. J Caring Sci. 2005; 19: 223229. PMid:16101850 http://dx.doi.org/10.1111/j.1471-6712.2005.00336.x

[12] Adams RJ, Smith BJ, Ruffin RE. Impact of the physician's participatory style in asthma outcomes and patient satisfaction. Ann Allergy Asthma Immunol. 2001; 86: 263-271. http://dx.doi.org/10.1016/S1081-1206(10)63296-6

[13] Arora NK, McHorney CA. Patient preferences for medical decision making: who really wants to participate? Med Care. 2000; 38: 335-341. PMid:10718358 http://dx.doi.org/10.1097/00005650-200003000-00010

[14] Davis MA, Hoffman JR, Hsu J. Impact of patient acuity on preference for information and autonomy in decision making. Acad Emerg Med. 1999; 6: 781-785. PMid:10463548 http://dx.doi.org/10.1111/j.1553-2712.1999.tb01206.x

[15] Efraimsson E, Rasmussen B, Gilje F, Sandman P. Expressions of power and powerlessness in discharge planning. J Clin Nurs. 2003; 12: 707-716. PMid:12919217 http://dx.doi.org/10.1046/j.1365-2702.2003.00718.x

[16] Guadagnoli E, Ward P. Patient participation in decision-making. J Soc Sc Med. 1998; 28: 577-584.

[17] SFS 1990:1404. Law of community paying responsibility for specific health and medical care. Stockholm. Swedish government. (In Swedish: Lag om kommunernas betalningsansvar för viss hälso- och sjukvård. SFS 1990:1404. Stockholm. Regeringskansliet).

[18] SFS 2003:193. Law of changing in law (1990:1404) of paying responsibility for specific health and medical care. Stockholm. Swedish government. (In Swedish: Lag om ändring i lagen (1990:1404) om kommunernas betalningsansvar för viss hälso- och sjukvård. Stockholm. Regeringskansliet).

[19] Kihlgren A. Older patients in transition -from home care towards emergency care. PhD thesis. Karolinska Institute. Stockholm, 2005.

[20] Hansagi H, Olsson M, Sjoberg S, Tomson Y, Goransson S. Frequent use of the hospital emergency department is indicative of high use of other health care services. Ann Emerg Med. 2001; 37: 561-567. PMid:11385324 http://dx.doi.org/10.1067/mem.2001.111762

[21] Rydwik E. Frandin K, Akner G. Effects of physical training on physical performance in institutionalised elderly patients (70+) with multiple diagnoses. Age Ageing. 2004; 33: 13-23. PMid:14870716 http://dx.doi.org/10.1093/ageing/afh001

[22] Thorslund M, Wånell SE. Aging and elder care. (In Swedish: Åldrandet och äldreomsorgen) Lund: Studentlitteratur, 2006.

[23] Kihlgren A, Fagerberg I, Skovdahl K, Kihlgren M. From home care to emergency hospital care: basis for decisions. J Clin Nurs. 2003; 12: 28-36. PMid:12519247 http://dx.doi.org/10.1046/j.1365-2702.2003.00682.x

[24] Patton MQ. Qualitative research \& Evaluation methods. Thousand Oaks, California: Sage Publications, 2004.

[25] Hsieh HF, Shannon SE. Three approaches to qualitative content analysis. Qual Health Res. 2005; 15: 1277-1289. PMid:16204405 http://dx.doi.org/10.1177/1049732305276687

[26] Lieblich A, Tuval-Mashiach R, Zilber T. Narrative research: reading, analysis, and interpretation. London: SAGE Publications, 1998.

[27] Sandelowski M. Real qualitative researchers do not count: the use of numbers in qualitative research. Res Nurs Health. 2001; 24: 230-240. PMid:11526621 http://dx.doi.org/10.1002/nur.1025 
[28] Chafe W. The analysis of discourse flow. In The handbook of discourse analysis. Shiffrin, Tannen, Heidi, eds. Oxford: Blackwell, 2001. PMid:11606467

[29] Proposition 1994/95:195. Primary care, private health care provider. Stockholm. Swedish government. (In Swedish: Primärvård, privata vårdgivare, Stockholm. Regeringskansliet).

[30] Lincoln Y \& Guba E. Naturalistic inquiry. New York: Sage, 1985.

[31] Polkinghorne D.E. An agenda for the second generation of qualitative studies. Int J Qual Stud Health Well-being. 2006 ; 1: 15-21.

[32] Virtanen H, Leino-Kilpi H, Salanterä S. Empowering discourse in patient education. Patient Educ Couns. 2007; 66: 140-146. PMid:17349769 http://dx.doi.org/10.1016/j.pec.2006.12.010

[33] Hedberg B. Decision making and communication in nursing practice. PhD thesis. Gothenburg's University, Gothenburg, Sweden, 2005.

[34] Zoffman V, Kirkevold M. Relationships and their potential for change developed in difficult type 1 diabetes. Qual Health Res. 2007; 17: 625-638. PMid:17478645 http://dx.doi.org/10.1177/1049732307301230

[35] McCormack B, Karlsson B, Dewing J, Lerdal A. Exploring person-centredness: a qualitative meta-synthesis of four studies. Scand. J Caring Sci. 2010; 24: 620-634. PMid:21050249 http://dx.doi.org/10.1111/j.1471-6712.2010.00814.x

[36] Adamsen L, Tewes M. Discrepancy between patients' perspectives, staff's documentation and reflection on basic nursing care. Scand. J Caring Sci. 2000; 14: 120-129. PMid:12035275 http://dx.doi.org/10.1080/02839310050162352

[37] Holtzmann JS, Timm H. The experiences of and the nursing care for breast cancer patients undergoing immediate breast reconstruction. Eur J Cancer Care. 2005; 14: 310-318. PMid:16098115 http://dx.doi.org/10.1111/j.1365-2354.2005.00578.x

[38] Zoffman V, Harder I, Kirkevold M. A person-centered communication and reflection model: sharing decision-making in chronic care. Qual Health Res. 2008; 18: 670-685. PMid:18223158 http://dx.doi.org/10.1177/1049732307311008

[39] Zoffman V, Kirkevold M. Life versus disease in difficult diabetes care: conflicting perspectives disempower patients and professionals in problem solving. Qual Health Res. 2005; 15: 750-765. PMid:15961873

http://dx.doi.org/10.1177/1049732304273888

[40] Gergen KJ. Social construction in context. London: SAGE publications, 2001.

[41] Burns N, Grove SK. The practice of nursing research: conduct, critique \& utilization. 4th ed. Philadelphia: Saunders, 2001.

[42] Whittemore R, Chase SK, Mandle CL. Validity in qualitative research. Qual Health Res. 2001; 11: 522-537. PMid:11521609 http://dx.doi.org/10.1177/104973201129119299 